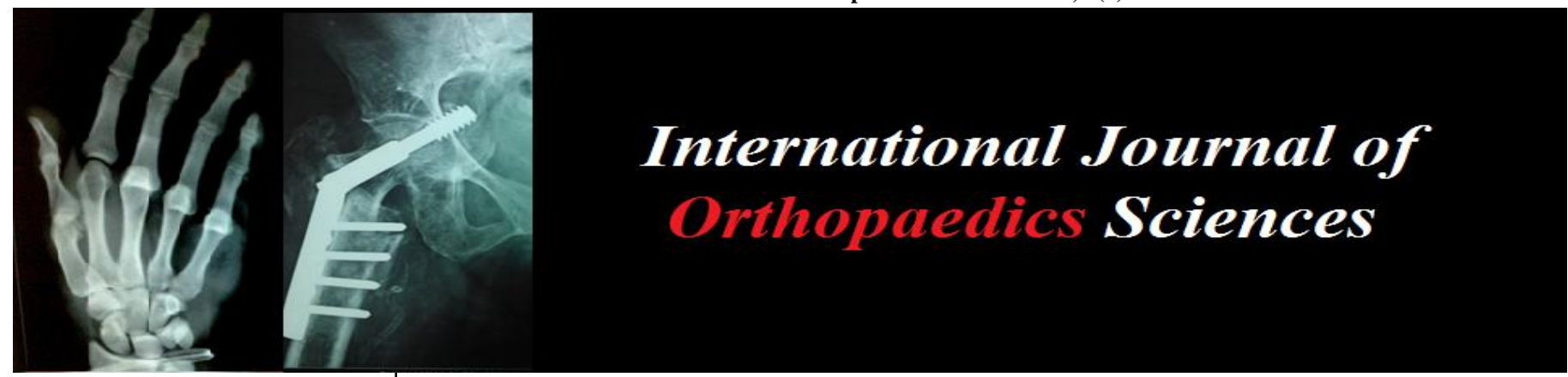

ISSN: $2395-1958$

IJOS 2018; 4(3): 91-94

(C) 2018 IJOS

www.orthopaper.com

Received: 19-05-2018

Accepted: 20-06-2018

\section{Dr. Prabhakar S}

Senior Assistant Professor,

Department Of Orthopedics,

Government Kilpauk Medical

College, Tamil Nadu, India

\section{Dr. Mohan G}

Senior Assistant Professor,

Department Of Orthopedics,

Government Kilpauk Medical

College, Tamil Nadu, India

\section{Dr. Kathir Azhagan S}

Resident Department of

Orthopedics, Government

Stanley Medical College,

Tamil Nadu, India

Dr. Karthikeyan M

Resident Department of

Orthopedics, Government

Kilpauk Medical College

Government Stanley Medical

College, Tamil Nadu, India

\section{Correspondence}

Dr. Kathir Azhagan S

Resident Department of

Orthopedics, Government

Stanley Medical College,

Tamil Nadu, India

\section{A prospective study of hybrid external fixation for proximal tibial fractures}

\author{
Dr. Prabhakar S, Dr. Mohan G, Dr. Kathir Azhagan S, Dr. Karthikeyan \\ M
}

DOI: https://doi.org/10.22271/ortho.2018.v4.i3b.19

\section{Abstract}

The treatment of proximal tibial fractures or intraarticular fractures are often challenging. Many surgeons encounter problems with wound healing even in closed tibial fractures because of co-existing soft tissue injuries. External fixation of these fractures have yielded satisfactory results, but some studies had reported problems in the achievement and maintenance of fracture reduction. Hybrid external fixator presents with mechanical characteristics that differ from other systems of external fixator. The mechanical characteristics of hybrid external fixation system can be called as SOLID ELASTIC. It is solid enough for stabilization and providing micromotion which enhances good callus formation the purpose of this study is to assess the utility of this hybrid external fixation system and to analyze the functional outcome, soft tissue healing and fracture union.

Keywords: Hybrid external fixation, proximal tibial fractures

\section{Introduction}

Intraarticular fractures of the tibial plateau and periarticular fractures of the proximal tibia, caused by high energy trauma pose a therapeutic dilemma. Such fractures are associated with extensive soft tissue damage with or without compound injury. The management of such high velocity injuries become a challenge to the trauma surgeons.

We present the use of hybrid external fixation system which includes Ilizarov ring fixator and AO rod external fixator connected with indigenously manufactured connecting clamps and short shafts augmented with or without minimal internal fixation ${ }^{[1]}$.

\section{Aim of the Study}

1. To assess the performance of the Hybrid External Fixator in the treatment of different types of proximal tibial fractures

2. To evaluate the functional outcome, soft tissue healing and fracture union and radiological outcome.

3. To evaluate the biomechanical and biological advantage of hybrid external fixator.

4. To assess the utility of the indigenously made connecting clamps.

\section{Materials}

From August 2010 to November 2011, 21 cases of periarticular fractures of the proximal tibia were treated by use of 5/8th Ilizarov ring, AO tubular external fixator and with indigenously manufactured connecting clamps \& short shaft in a hybrid mode. All cases were prospectively followed up and studied. Almost all the cases (99\%) had sustained Road traffic Accidents (high velocity injuries) except one case which had sustained injury by fall of cement wall over her leg. Minimum follow up - 1.5 months, maximum follow up -12 months, mean follow up -6.42 months. All fractures were followed according to a protocol. All fractures were treated with either CLOSED REDUCTION AND HYBRID EXTERNAL FIXATION OR WITH MINIMAL OPEN REDUCTION AND A HYBRID SYSTEM. The study group was consisted of 16 males $(76 \%)$ and 5 females $(24 \%)$ with an average age for males of 43.06 years (range 25 to 65 ) and for females of 53.4 years (range 41 to 59).All the patients were in the age group of 26 to 65 years, mean age is 43.09 . 
Proximal tibial plateau fractures were classified according to the Schatzkar classification and open fractures by Gustilo Anderson classification. There were four type 4 fractures, four type 5, thirteen type 6 fractures and four Grade 3 B open fractures.

Table 1: Mode of Injury

\begin{tabular}{|c|c|c|c|}
\hline S. No. & Mode Of Injury & no. of patients & percentage \\
\hline 1. & RTA & 19 & $99 \%$ \\
\hline 2. & FALL & 2 & $1 \%$ \\
\hline
\end{tabular}

Table 2: Sex

\begin{tabular}{|c|c|c|c|}
\hline S. No. & Sex & No. of Patients & Percentage \\
\hline 1 & Male & 16 & $76.19 \%$ \\
\hline 2. & Female & 5 & $23.80 \%$ \\
\hline
\end{tabular}

Table 3: Age Distribution

\begin{tabular}{|c|c|c|c|}
\hline S. No. & Age & No. of Patients & Percentage \\
\hline 1. & $20-30$ & 25 & $9.25 \%$ \\
\hline 2. & $31-40$ & 5 & $19.04 \%$ \\
\hline 3. & $41-50$ & 5 & $23.80 \%$ \\
\hline 4. & $51-60$ & 8 & $39.09 \%$ \\
\hline 5. & $61-70$ & 1 & $9.25 \%$ \\
\hline
\end{tabular}

Table 4: Fracture Classification

\begin{tabular}{|c|c|c|c|}
\hline S. No. & fracture type & No. of Patients & Percentage \\
\hline 1. & Closed & 17 & $80.95 \%$ \\
\hline 2. & Compound & 4 & $19.04 \%$ \\
\hline
\end{tabular}

Table 5: Schatzkar Classification

\begin{tabular}{|c|c|c|c|}
\hline S. No. & Fracture Type & No. of Patients & Percentage \\
\hline 1 & S- IV & 4 & 19.04 \\
\hline 2. & S- V & 4 & 19.04 \\
\hline 3. & S-VI & 13 & $61.90 \%$ \\
\hline
\end{tabular}

The pre-operative radiographs were used to classify the fractures according to Schatzkar's classification system. There were 4

S-4(19.04\%), 4 S-5(19.04\%), and 13 S-6(61.90\%). Seventeen Patients were closed $(81 \%)$ and 4 four were open fractures (19\%). All the open fractures were Gr 3 B compound fractures. Peroneal nerve injury never presented in any patient.

Compound fractures were treated with immediate debridement and hybrid external fixator. Closed fractures were initially treated with limb elevation and splintage to allow for subsidence of soft tissue swelling for 3-5 days. Subsequently fractures were treated by hybrid external fixator. Prophylactic antibiotics were administered intravenously in all cases. In the open fracture cases, antibiotics were prescribed as necessary for the first days and subsequently replaced according to the culture results. All open fractures received initially a combination of a ceftriaxone with an aminoglycoside.

\section{Method \\ Pre OP Clinical Evaluation}

Detailed history was elicited in all patients. All the patients had RTA with high velocity injury. Clinically injury was evaluated as simple or compound injuries. In case of compound injury wound was thoroughly debrided and planned for immediate hybrid fixation. In case of closed tibial fractures the soft tissue injury was assessed and the compartment syndrome was ruled out. Limb was elevated till the time of surgery.

\section{Radiological Evaluation \& Grading}

Careful radiological assessment was carried out regarding fracture pattern (simple, comminuted, intraarticular involvement) and any loose fragments presented inside the joint. If any loose fragment was presented inside the joint it was evaluated thoroughly by CT scan. Radiologically the proximal tibial fractures were classified according to Schatzkar types and open fractures by Gustilo Anderson classification. Undisplaced articular fragments were reduced with plain wires and displaced articular fragments were reduced with mini open method.

\section{Selection of Cases}

\section{Inclusion Criteria}

1. Tibial plateau fractures according to Schatzkar classificafion Type 4, Type 5 and Type 6.

2. Proximal 1/4 extra articular tibial fractures (severely comminuted )

3. Open Proxial tibial fractures according to Gustillo Anderson Classification Gr 2, Gr 3A, 3B, 3C

4. Proximal tibial fracture with compartment syndrome after Fasciotomy.

5. High velocity proximal tibial fracture in impending compartment syndrome.

6. Patients age over 18 years and ability to walk without assistance before injury.

\section{Exclusion Criteria}

1. Schatzkar type 1 , type 2 and type 3

2. More than 2 weeks old fractures.

3. Bilateral tibial plateau fractures.

4. Polytrauma patients with tibial plateau fractures requiring prolonged ICU care.

5. Proximal tibial fractures with neurological disorder.

6. Proximal tibial fractures with paralytic disorder.

Preoperative planning, surgery, post-operative management given and the outcome assessed based on Neer's rating system for evaluation of $\mathrm{knee}^{3}$

\section{Results}

After analyzing the above characters we have obtained Excellent results in 7 patients (33. 3\%), Good in 9 (42.35\%), Fair in $4(19.04 \%)$, Failure in $1(4.76 \%)$ patient.

Table 6: Results

\begin{tabular}{|c|c|c|c|}
\hline S. No. & No. of Patients & Percentage & Result \\
\hline 1. & 7 & $33.33 \%$ & excellent \\
\hline 2. & 9 & $42.85 \%$ & good \\
\hline 3. & 4 & $19.04 \%$ & fair \\
\hline 4. & 1 & $1.76 \%$ & failure \\
\hline
\end{tabular}

Union was determined by the presence of a bridging callus on the follow up radiographs and by the clinical impression of stability.

One patient who had severe comminuted fracture involving whole tibia complicated with severe infection in leg and loss of vascularity and finally ended up with amputation. All associated ligamentous and meniscal lesions were repaired at a second stage after fracture healing. All fractures healed, with an average time of treatment with the frame of 18 weeks. The external fixator was tolerated for the entire treatment period in all cases. 
Pin track infection occurred in 2 patients. Out of 2 patients one patient got deep infection in knee joint. In 4 patients superficial infection or limited to soft tissues and did not extend to the bone \& resolved with pin track care and oral antibiotics. Knee range of motion occurred from $0-120$ degree to 10 - 90 degree (Average 5 to 105 degrees). In 2 cases varus malunion occurred. However functionally knee ROM and walking were not affected. Early weight bearing by the patient could be the main reason for varus malunion.

\section{Complications}

In our case series we encountered the following complications

Table 7

\begin{tabular}{|c|c|c|}
\hline S. No. & Complications & No. of Patients \\
\hline 1. & Varus collapse & 2 \\
\hline 2. & Deep infection & 1 \\
\hline 3. & Delayed union & 1 \\
\hline 4. & Severe septicemia with amputation & 1 \\
\hline 5. & No complications & 16 \\
\hline
\end{tabular}

To summarize, the advantages of hybrid external fixator are

1. Minimally invasive procedure

2. Very good preservation of soft tissues

3. Better anchorage of tensioned wires than half pins in cancellous bone area and they give better stability.

4. Easy application of half pins in diaphysis without neurovascular injury.

5. Early mobilization of knee joint.

6. Good skin care and easy application of flap cover.

7. Good acceptance to patient.

The disadvantages of hybrid fixator are

1. Risk of articular infection if pins are applied very close to joint.

2. Tough to obtain articular reduction.

3. Radio opaque ring obstructs radiological image.

\section{Discussion}

High velocity periarticular fractures of tibia closed as well as compound injuries are complex to treat. Management of these fractures are difficult and varies from surgeon to surgeon. Such injuries are usually associated with soft tissue injury and marked comminution of articular surface. Conservative treatment of comminuted high energy proximal tibial fractures as proven to be inferior when compared to operative treatment. Internal fixation, despite the advantages of direct visualization, proper and stable reduction of the articular surface as well as the acute repair of soft tissue injuries, presents also serious disadvantages, including skin and soft tissue necrosis caused by surgical manipulations on an already damaged soft tissue envelope and the high rate of infection, which may compromise the final result. Young and Barrack, in their series of dual plating for complex bicondylar tibial plateau fractures reported an $88 \%$ deep infection rate ${ }^{[11,12]}$. Steven et al presented several transoperative - post operative complications ${ }^{[17]}$. Certain autors have treated bicondylar tibial plateau fractures by means of a lateral fixed angular plate through a single lateral approach, thus Avoiding medial periosteal striping $[13,14]$. Jiang $\mathrm{R}$ et al, in their prospective study comparing locked plates, for the repair of bicondylar tibial plateau fractures reported similar results for the two groups $^{15}$. Neverthless as presented by Higgins et al, bicondylar fractures stabilized by means of a fixed angle platre present a higher rate of subsidence compared to dual plating stabilized fractures ${ }^{[16]}$.

The external fixation as a define treatment for the polytrauma patient with multiple osseopus and soft tissue injuries has been described in the literature ${ }^{(37,38)}$ Certain authoris believe that external fixation should be limited to biocondylar tibial fractures with a compromised soft-tissue envelope, as a temporary stabilizing technique,prior to delinite treatment ${ }^{[11]}$. In the last 2 decades, the evaolution of devices and techniques of external fixation has led many surgeons to apply the principles of biologic osteosynthesis and minimally invasive surgery for the treatment of comminuted tibial plateau fractures [5, 11]. The development of circular and hybrid frames, the capability of axial, lateral compression anddynamization, the development ofolive wires have offered new possibilities to the external fixators for the treatment of complexfractures ${ }^{[12]}$. Mahadena et al, comparing external to internal fixation, concluded that hybrid external fixation possessestheoretical advantages in terms of the soft tissues protection; however the benefit over internal fixation ismodest as far as accuracy of reduction is concerned ${ }^{[13]}$. Chin et al presented $38.9 \%$ good / excellent, and $61.1 \%$ fair / poor results in his type $\mathrm{V}$ and VI fractures series ${ }^{[14]}$. Catagni et al, in their series of high-energy Schatzker V and VI tibial plateau fractures treated with circular external fixator, reported excellent and good results in 30 (50.85\%) and 27 $(45.766 \%)$ patients respectively ${ }^{(4)}$. In a similar study on type $\mathrm{V}$ and VI tibial plateau fractures, Katsenis et al recorded excellent or good final Canadian Orthopaedic Trauma Association, in a multicenter, prospective, randomized clinical trial of $83 \mathrm{~S}-\mathrm{V}$, VI tibial platau fractures treated with internal or external fixation, reported similar quality of osseous reduction and ROM for both groups but lower rate of early postoperative complications and improved HSSscores for the external fixation group at the six months' follow up. However, at the two years' follow up, no significant difference in ROM, HSS scores, WOMAC and SF-36 was observed between the two groups ${ }^{[15]}$. As far as minor complications are concerned, Hutson et al, in a meta-analysis of 16 studies with a total of 568 patients found pin site infection rates of $10 \%$ for tibial plateau fractures (45). This number is similar to the rate of pin tract infection.

Uniplanar external fixators do not provide stability to the comminuted fractures. The goal of surgical treatment of these periarticular fracture is to provide stable fixation, thus allowing early joint motion and to obtain articular congruity. Early joint motion is probably the single most important factor in promoting cartilage nutrition. Fixation must be stable enough to allow early motion and to minimize the wound complication ${ }^{[10]}$.

The choice of which hybrid external fixator to use should be made based not only on stiffness but also on ease of clinical application, patient comfort and cost.

In our study 21 cases of tibial plateau fractures were treated by hybrid external fixation. The use of cannulated cancellous screws and olive wires helped in achieving interfragmentary compression and articular congruity. Along with use of $5 / 8^{\text {th }}$ ring in proximal tibia helped in achieving stable fixation and early joint motion ${ }^{[7,10]}$.

In present study we obtained the excellent results in 7 patients, Good in 9, Fair in 4, Failure in 1 patient. One patient who had severe comminuted fracture involving whole tibia complicated with severe infection in leg and and landed up with septicemia, finally ended up with amputation. One patient went with varus collapse in knee joint. One patient got 
deep infection for which the patient underwent knee aspiration \& subsequently sent the specimen for biochemical and microbiological analysis. Then accordingly treated with IV antibiotics and finally recovered satisfactorily with good range of movements.

One pure metaphyseal fracture with severe comminution took long time to consolidate approximately 22 weeks. This finding could reflect the slow healing potential of metapyseal fracture may be because of increased stability of the frame or due to intactness of the tibia.

The use of small diameter $\mathrm{K}$ wires wit $5 / 8^{\text {th }}$ ring in the proximal tibia reduces the complication rate especially pin track infection. Loosening of the wire was not seen in our study. The combination of a $5 / 8^{\text {th }}$ ring and $\mathrm{AO}$ tubular rod does not affect the stability of the construct ${ }^{[6,8]}$. Such hybrid combination helps in achieving articular co ngruity besides providing stable fixation which allows for early movements of the joint. Few hybrid external fixation systems are commercially available, they are very expensive and are not easily available. In this study we have used combination of indigenously manufactured connecting clamps and short shafts along with $5 / 8^{\text {th }}$ Ilizarov ring and $\mathrm{AO}$ tubular rods. Thus this hybrid frame is easy to apply, versatile and significantly less expensive within the reach of poor patients.

\section{Conclusion}

The hybrid external fixator method we had applied is safe as regards of soft tissue healing and the limited number of complications associated directly to this method of application. We believe that the use of Hybrid external fixation, as a definite treatment, for high - energy proximal tibia bicondylar fractures proved to be beneficial. So we recommend a mini open reduction with percutaneous cannulated cancellous screw (one or two for securing interfragmentary compression) or olive wires with hybrid external fixator. This is the best method for closed (Schatzkar type $4,5,6$ ) as well as open proximal tibial fractures.

\section{References}

1. Weiner LS, Kelley M, Yang E. The use of combination internal fixation and hybrid external fixation in severe proximal tibial fractures. J Orthop Trauma. 1995; 9(3):244-50.

2. Savolainen VT, Pajarinen J, Hirvensalo E, Lindahl J Hybrid external fixation in treatment of proximal tibial fractures: a good outcome in AO/ASIF type-C fractures. Arch Orthop Trauma Surg. 2010; 130(7):897-901.

3. Insall JN, Dorr LD, Scott RD, Scott WN. Rationale of the Knee Society clinical rating system. Clin Orthop. 1989; 248:13-14.

4. Schatzker J. Fractures of the tibial plateau. In Chapman MW, Bray TJ, Spiegel PG, Green SA (eds). Operative Orthopaedics. JB Lippincott; Philadelphia, 1988, 671684.

5. Stamer DT, Schenk R, Staggers B, Aurori K, Aurori B, Behrens FF. Bicondylar tibial plateau fractures treated with a hybrid ring external fixator: a preliminary study. J Orthop Trauma. 1994; 8:455-461.

6. Behrens F, Johnson W. Unilateral external fixation. Methods to increase and reduce frame stiffness. Clin Orthop Relat Res. 1989; 241:48-56.

7. Caja VL, Larsson S, Kim W, Chao EY. Mechanical performance of the Monticelli-Spinelli external fixation system. Clin Orthop Relat Res. 1994; 309:257-266.

8. Hammer R, Helland P. Improved external skeletal fixation for unstable fractures. Clin Orthop Relat Res. 1987; 217:230-242.

9. DeCosterTA, CrawfordMK,Kraut MA. Safe extracapsular placement of proximal tibia transfixation pins. J Orthop Trauma. 1999; 13:236-240.

10. Khalily C, Voor MJ, Seligson D. Fracture site motion with Ilizarov and "hybrid" external fixation. J Orthop Trauma. 1998; 12:21-26.

11. Young MJ, Barrack RL: Complications of internal fixation of tibial plateau fractures. Orthop Rev. 1994; 23:149-54

12. Keoch P, Kelly C, Cashman WF, McGuinness AJ, O Rourke SK: Percutaneous screw fixation of tibial plateau fractures. Injury. 1992; 23:387-389.

13. Partenheimer A, Gosling T, Muller M. Management of bicondylar fractures of tibial plateau with unilateral fixed angle plate fixation. Unfallachirug. 2007; 110:675-83.

14. Gosling T, Schandelmaier P, Muller M. Single lateral locked screw plating of bicondylar tibial plateau fractures. Clin Orthop Relat Res. 2005; 439:207-14

15. Jiang R, Luo CF, Wang MC: A comparative study of LISS fixation and two incision double plating for the treatment of bicondylar tibial plateau fractures. Knee. 2008; 15:139-143

16. Higgins TF, Klatt J. Biomechanical analysis of Bicondylar tibial plateau Fixation: How does lateral locking plate fixation Compare to Dual Plate Fixation? J Orthop Trauma. 2007; 21:301-306

17. Stevens DG, Behany R. The Long Term Functional Outcome of Operatively Treated Tibial Plateau Fractures. Orthop Trauma. 2001; 15:312-320. 